\title{
Chronic recurrent multifocal osteomyelitis exhibiting predominance of periosteal reaction
}

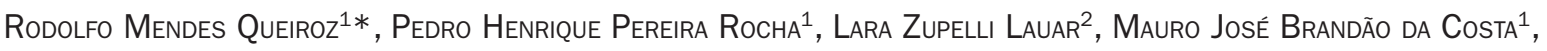 \\ Claudio Benedini Laguna ${ }^{1}$, Rafael Gouvêa Gomes de Oliveira ${ }^{1}$
}

1Department of Radiology and Imaging Diagnosis, Documenta, Hospital São Francisco, Ribeirão Preto, SP, Brazil

2Division of Radiology and Imaging Diagnosis, Department of Internal Medicine, Hospital das Clínicas da Faculdade de Medicina de Ribeirão Preto da Universidade de São Paulo, Ribeirão Preto, SP, Brazi

\begin{abstract}
SUMMARY
Study conducted at Documenta Centro Avançado de Diagnóstico por Imagem, Hospital São Francisco Ribeirão Preto, SP, Brazil

Article received: 9/11/2016 Accepted for publication: 10/4/2016

*Correspondence: Address: Rua Bernardino de Campos, 980 Ribeirão Preto, SP - Brazil Postal code: 14015-130 rod_queiroz@hotmail.com

Chronic recurrent multifocal osteomyelitis is an idiopathic nonpyogenic autoinflammatory bone disorder involving multiple sites, with clinical progression persisting for more than 6 months and which may have episodes of remission and exacerbation in the long term. It represents up to $2-5 \%$ of the cases of osteomyelitis, with an approximate incidence of up to 4/1,000,000 individuals, and average age of disease onset estimated between 8-11 years, predominantly in females. The legs are the most affected, with a predilection for metaphyseal regions along the growth plate. We describe the case of a female patient, aged 2 years and 5 months, with involvement of the left ulna, right jaw and left tibia, showing a predominance of periosteal reaction as main finding.
\end{abstract}

Keywords: osteomyelitis, chronic, multifocal, recurrent, periosteal.

\section{Case report}

A female patient aged 2 years and 5 months, being investigated due to pain and swelling in the left forearm for one month. Her parents denied episodes of fever, trauma, and other comorbidities. On physical examination, the child presented normal weight, normal skin color, she was well-hydrated, acyanotic, breathing normally and in good general conditions. Blood counts analyzed in the previous month revealed mild leukocytosis and normocytic normochromic anemia. Levels of C-reactive protein (CRP) and erythrocyte sedimentation rate (ESR) were slightly elevated.

Computed tomography (CT) of the left forearm without intravenous contrast revealed a periosteal reaction and a small area of loss of cortical compaction, especially in the ulna (Figure 1A).

A biopsy of the left ulna was performed with results describing signs suggestive of chronic osteomyelitis. Culture of the biopsy material did not show growth of microorganisms.

Empirical antibiotic therapy was used starting one month after diagnosis, but there was no change in clinical status. A new biopsy was performed in the third month, showing the same findings associated with negative blood culture. Radiographs of the left forearm from the second to the fifth month showed progression of the multilamellar periosteal reaction to a solid type (Figure 1B).

Chest radiography, echocardiography, levels of TSH, T4, IgG, IgA, IgM and complement components were all normal. A hypothesis of chronic recurrent multifocal osteomyelitis (CRMO) was suggested and thus treated with ibuprofen combined with methotrexate, later replaced with sulfasalazine.

Between the eighth and ninth month, pain and swelling appeared in the right mandibular region and in the left leg. A facial CT scan showed mainly periosteal reaction at the right mandibular angle with mild bone sclerosis (Figure 2). CT scan of the left leg also characterized a periosteal reaction in the tibial diaphysis with a small area of cortical alteration (Figure 3), similar to that found in the ulna.

After 6 months of therapy, there was clinical and general laboratory improvement, with left forearm radiography in the $11^{\text {th }}$ month showing a regression of the periosteal reaction, despite persistence of cortical thickening.

\section{Discussion}

CRMO is an idiopathic nonpyogenic autoinflammatory bone disorder involving multiple sites, with clinical progression persisting for more than six months and which 


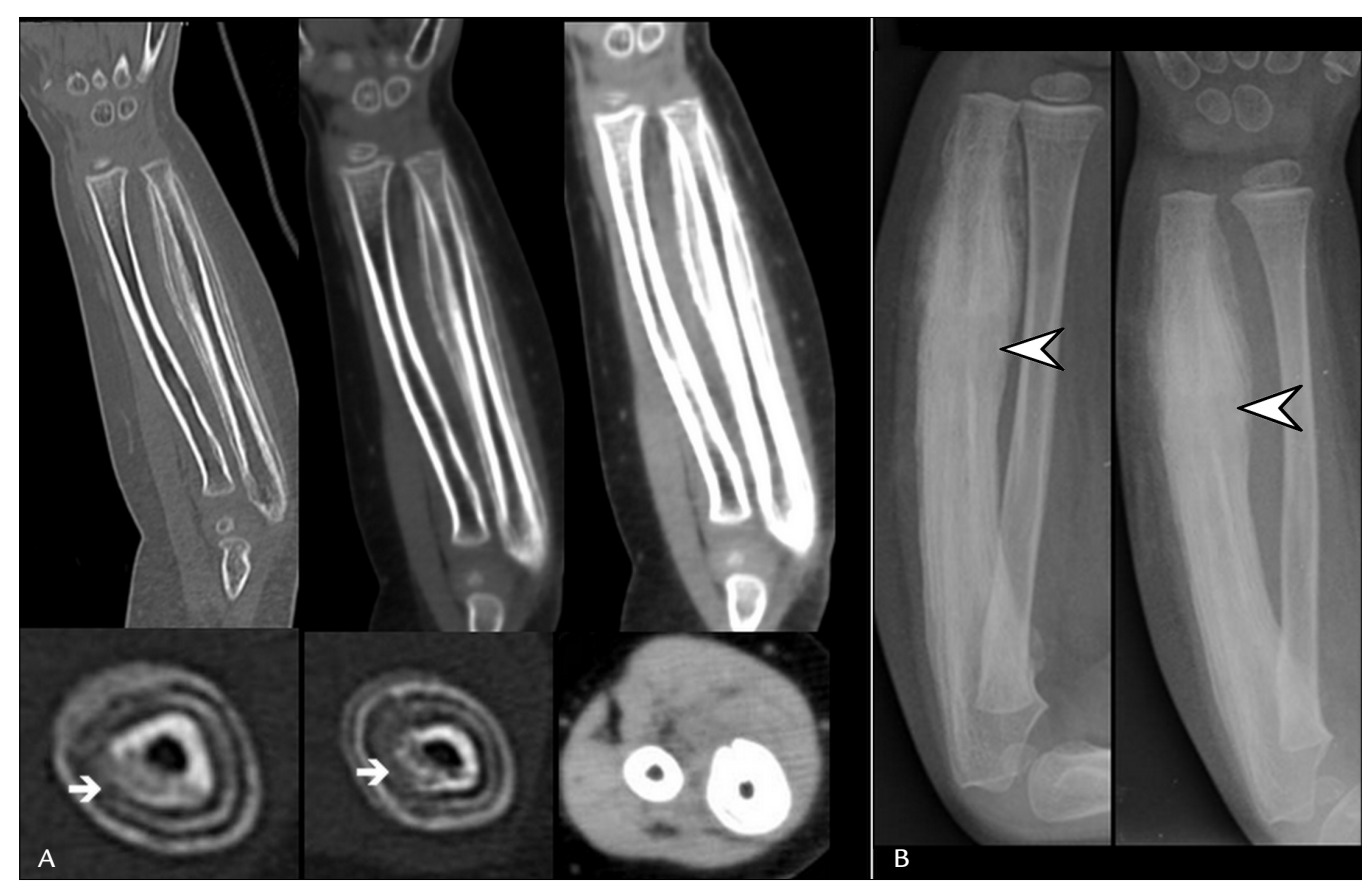

FIGURE 1 A. CT scan of the left forearm without administration of intravenous contrast medium showing intense metaphyseal and predominantly diaphyseal multilamellar periosteal reaction in the ulna and small area of cortical bone irregularity with loss of compaction (white arrows). B. Radiography of the left forearm after biopsies showing the periosteal reaction in the ulna and the point of collection of bone material (arrowheads).

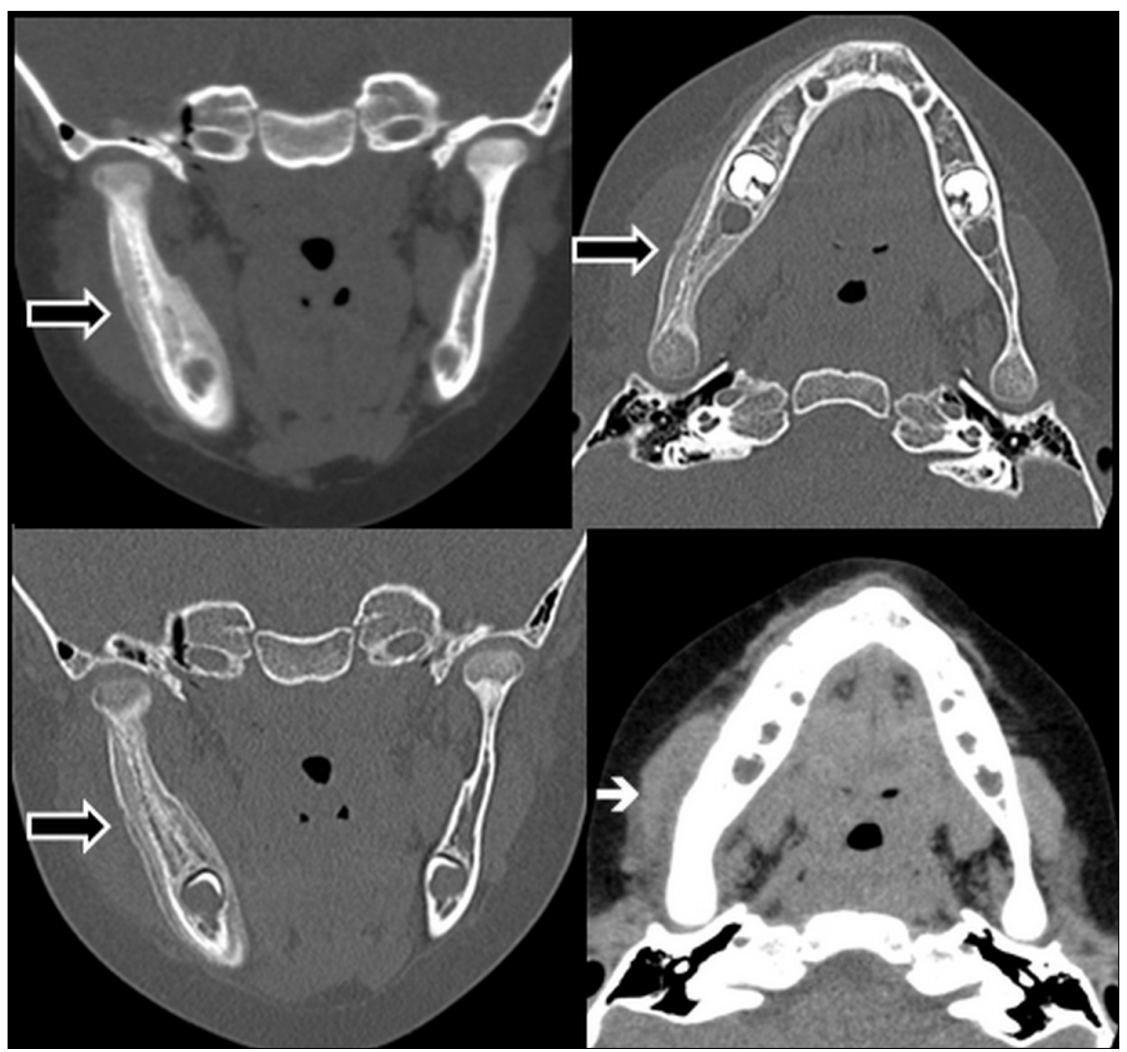

FIGURE 2 CT scan of the face mainly characterized by periosteal reaction in the right mandibular angle with tenuous bone sclerosis (black arrow), in addition to a discrete volumetric increase and densification of adjacent soft tissues, suggesting edema (white arrow). 


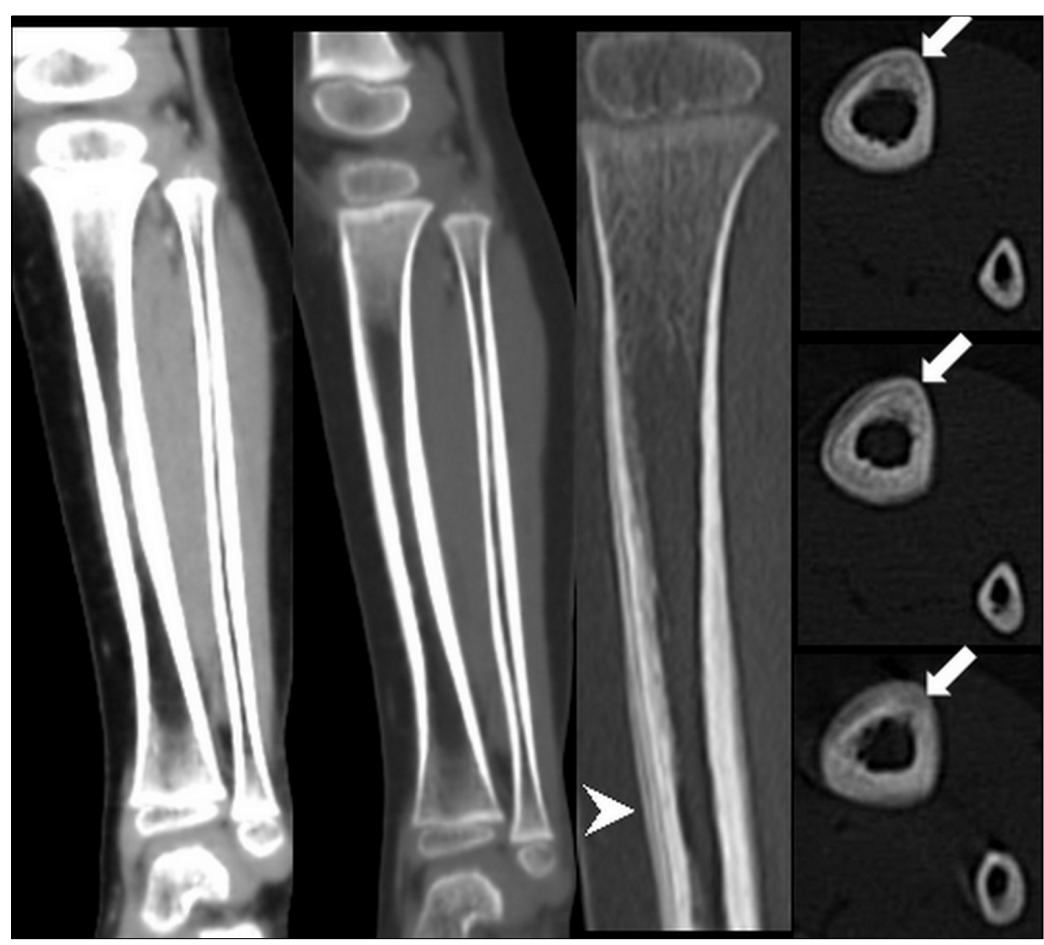

FIGURE 3 CT scan of the left leg demonstrating a periosteal reaction in the tibial diaphysis (arrowhead and white arrows) with a small area of cortical alteration similar to that found in the ulna (white arrows).

may have episodes of remission and exacerbation in the long term. ${ }^{1}$ Some studies suggest that CRMO and other diseases such as SAPHO syndrome and Garré's osteomyelitis are variants of the same pathology, with their respective sites, characteristics and prevalent age groups. ${ }^{1-3}$

It represents up to $2-5 \%$ of the cases of osteomyelitis, ${ }^{2}$ with an approximate incidence of up to 4/1,000,000 individuals,${ }^{4}$ and average age of disease onset estimated between 8-11 years, predominantly in females (64-83\%). ${ }^{1,-6}$

Signs and symptoms include local inflammation with pain and edema, episodes of mild fever, which do not profoundly affect the general condition of the patient, and common asymptomatic lesions (17-56\%). ${ }^{1}$ Positive personal or family history of psoriasis, palmoplantar pustules, chronic inflammatory bowel disease or other autoimmune diseases are also common (up to $50 \%$ of cases). ${ }^{7-9}$

In active disease, laboratory tests show a mild to moderate increase in ESR and CRP, with normal blood count or, more rarely, mild leukocytosis and anemia. Typically, the levels of complement components (C3 and C4), IgA and IgM do not change. ${ }^{1,5,7,8,10}$ HLA-27 is positive in less than $30 \%$ of the patients. ${ }^{1,9,11}$

Performing a biopsy is important to rule out other diagnostic hypotheses. Histological findings are nonspecific and often similar to those found in septic osteomyelitis, but with no evidence of infection by any microorganism. ${ }^{1,2-10}$
Imaging tests such as radiography, CT, magnetic resonance imaging (MRI) and scintigraphy are some of the diagnostic tools. The latter two are most commonly used to rule out other diseases and to detect asymptomatic sites employing whole body screening techniques. ${ }^{1,46,12}$

Long and tubular bones are preferentially affected, especially the lower limbs. ${ }^{1,4-6}$ In a study by von Kalle et al., the frequencies found for lesions by bone segment were: meta-epiphyseal (31\%), metaphyseal (30\%), epiphyseal (19\%), meta-diaphyseal (10\%), diaphyseal (1.8\%), apophyseal (1.8\%), and epimetadiaphyseal (1.4\%). ${ }^{4}$ According to a study by Fritz et al., diaphyseal involvement can reach $14 \%{ }^{6}$ A predilection for regions in the metaphysis next to the growth plate is noted, and there is symmetry in at least $25 \%$ of the lesions. ${ }^{1,4-6}$ The most common articular findings are joint effusion and synovitis, most often in the knees and ankles, often bilaterally, sometimes with affections in the sacroiliac joints. ${ }^{6}$

Analyzing the absolute number of lesions reported, the most frequently affected sites include tibia (15-31\%), spine (7-30\%), femur (11-23\%), tarsal and metatarsal bones (8-19\%), fibula (2-14\%), hip (5-12\%), clavicle (5-7\%), radio (4-5\%) and ulna (3-4\%), and ribs (1-4\%)., ${ }^{1,-6}$

In general, imaging tests show small lytic or sclerotic lesions, or a combination of both. Mixed lesions are usually characterized by lytic, circumscribed areas with sur- 
rounding sclerosis. There is also the possibility of progression with locoregional cortical hyperostosis, in addition to simple, solid or multilamellar laminar periosteal reaction (7-48\%), which may be the most obvious alteration in long and diaphyseal bones. Edema in bones and surrounding soft parts is usually present. ${ }^{1,4-6}$

Jansson et al. proposed the diagnosis of CRMO based on criteria, being positive if two major or one major and three minor criteria are met, $, 1,2,7,8$ as follows:

- Major criteria - osteolytic/sclerotic lesions evident in imaging tests; multifocal bone lesions; presence of palmoplantar pustulosis or psoriasis; sterile bone biopsies with signs of inflammation and/or sclerosis. ${ }^{1,2,7,8}$

- Minor - normal blood count and leukogram; good general health; discrete/moderate elevation of ESR and CRP; disease course greater than 6 months; hyperostosis; association with other autoimmune diseases besides psoriasis and palmoplantar pustulosis; first or second degree relative with autoimmune or autoimmune disease. ${ }^{1,2,7,8}$

The most widely used treatment with the best results is nonsteroidal anti-inflammatory drugs (NSAIDs). Other therapeutic possibilities include the use of steroids, methotrexate, sulfasalazine, bisphosphonates, infliximab, colchicine, hyperbaric oxygen therapy, alpha and gamma interferons. . $, 2,4-11^{2}$

CRMO is not usually lethal, but at least $20 \%$ of cases develop with sequelae. Chronic pain, pathological fractures, growth deformities, focal increase of bone volume, collapse in varying degrees of vertebral bodies with repercussion in the spinal canal are some of the possible complications, the latter being more serious. ${ }^{1,46}$

\section{Resumo}

Osteomielite crônica multifocal recorrente exibindo predomínio de reação periosteal

Osteomielite crônica multifocal recorrente é uma desordem autoinflamatória óssea idiopática não piogênica, envolvendo vários sítios e com evolução clínica persistin- do por mais de 6 meses, podendo apresentar episódios de remissão e exacerbação em longo prazo. Representa de 2 a $5 \%$ das osteomielites, com incidência aproximada de até 4/1.000.000, com idade média de apresentação estimada entre 8 e 11 anos, predominando no gênero feminino. Os membros inferiores são os mais afetados, com predileção para regiões metafisárias junto à fise. Descrevemos um caso da doença em uma menina de 2 anos e 5 meses de idade, com acometimento de ulna esquerda, mandíbula à direita e tíbia esquerda, exibindo predomínio de reação periosteal como achado principal.

Palavras-chave: osteomielite, crônica, multifocal, recorrente, periosteal.

\section{References}

1. Jansson A, Renne ED, Ramser J, Mayer A, Haban M, Meindl A, et al. Classification of non-bacterial osteitis: retrospective study of clinical, immunological and genetic aspects in 89 patients. Rheumatology (Oxford). 2007; 46(1):154-60

2. Campos TA, Rebelo J, Maia A, Brito I. Osteomielite multifocal crónica recorrente: uma entidade a reconhecer!. Arq Med. 2011; 25(5-6):183-5.

3. Guerra JG, Lima FAC, Macedo LMG, Rocha AAL, Fernandes JF. [SAPHO syndrome: rare or under-diagnosed?] Radiol Bras. 2005; 38(4):265-71.

4. von Kalle T, Heim N, Hospach T, Langendörfer M, Winkler P, Stuber T. Typical patterns of bone involvement in whole-body MRI of patients with chronic recurrent multifocal osteomyelitis (CRMO). RoFo. 2013; 185(7):655-61.

5. Falip C, Alison M, Boutry N, Job-Deslandre C, Cotten A, Azoulay R, et al. Chronic recurrent multifocal osteomyelitis (CRMO): a longitudinal case series review. Pediatr Radiol. 2013; 43(3):355-75.

6. Fritz J, Tzaribatchev N, Claussen CD, Carrino JA, Horger MS. Chronic recurrent multifocal osteomyelitis: comparison of whole-body MR imaging with radiography and correlation with clinical and laboratory data. Radiology. 2009; 252(3):842-51.

7. Tlougan BE, Podjasek JO, O'Haver J, Cordova KB, Nguyen XH, Tee R, et al. Chronic recurrent multifocal osteomyelitis (CRMO) and synovitis, acne, pustulosis, hyperostosis, and osteitis (SAPHO) syndrome with associated neutrophilic dermatoses: a report of seven cases and review of the literature. Pediatr Dermatol. 2009; 26(5):497-505.

8. Ferraria N, Marques JG, Ramos F, Lopes G, Fonseca JE, Neves MC. Osteomielite crónica multifocal recorrente: série de 4 casos clínicos tratados com bifosfonatos. Acta Reumatol Port. 2014; 39(1):38-45.

9. Stern SM, Ferguson PJ. Autoinflammatory bone diseases. Rheum Dis Clin North Am. 2013; 39(4):735-49.

10. Paim LB, Liphaus BL, Rocha AC, Castellanos AL, Silva CA. [Chronic recurrent multifocal osteomyelitis of the mandible: report of three cases]. J Pediatr (Rio J). 2003; 79(5):467-70.

11. Machado LG, Capp AA, Paes MAS, Oliveira RB, Bonfante HL. [Pamidronate treatment in SAPHO syndrome]. Rev Bras Reumatol. 2005; 45(6):409-12.

12. Teixeira SR, Elias Junior J, Nogueira-Barbosa MH, Guimarães MD, Marchiori E, Santos MK. Whole-body magnetic resonance imaging in children: state of the art. Radiol Bras. 2015; 48(2):111-20. 